\title{
Ultraviolet Exposure and Photokeratitis Complaints among Informal Welding Workers in Depok, West Java, Indonesia
}

\author{
Maria K I J Yustheresani ${ }^{1}$, Fajaria Nurcandra ${ }^{1}$, Azizah Musliha Fitri ${ }^{1}$, Annisa Ika Putri ${ }^{2}$, Dyah Utari ${ }^{1}$
}

${ }^{1}$ Public Health Studies, Faculty of Health Science, Universitas Pembangunan Nasional Veteran Jakarta, Indonesia

${ }^{2}$ Faculty of Science, Athena Institute, Vrije Universiteit, The Netherlands

\begin{abstract}
One of the photokeratitis risk factors is acute reversible radiation of ultraviolet (UV) rays, which injure the cornea's epithelial tissue. Informal welding workers are susceptible populations to UV rays exposure. This study aimed to confirm the influence of UV radiation exposure on photokeratitis complaints in welding workers in Cimanggis, Depok, West Java. A cross-sectional study was conducted from February to June 2019 and used to select 100 welding workers purposively. A semi-structured questionnaire was used to determine photokeratitis complaints, age, education level, eye protection, safety knowledge, and work period; the UV radiation measured by A UV meter. Data were analyzed using a logistic regression test. This study found the proportion of photokeratitis to be $84.0 \%$, with $76.0 \%$ of UV radiation exceeding the Threshold Limit Values (TLV). The logistic regression test showed a significant effect of UV radiation on photokeratitis after controlling confounding variables (education level, eye protection, safety knowledge, and welding distance) $(p$-value $=0.006 ;$ AdjOR = 7.236; $95 \%$ Cl: 1.74-30.07). It can be concluded that UV radiation, more than TLV, constitutes the primary risk factor for photokeratitis complaints. Risks for photokeratitis were influenced by low education level, poor eye protection, limited safety knowledge, and welding distance $\leq 45 \mathrm{~cm}$.
\end{abstract}

Keywords: photokeratitis, radiation, ultraviolet, welding, worker

\section{Introduction}

Photokeratitis is an eye disease or acute effect of ultraviolet (UV) radiation, which causes inflammation in the cornea. ${ }^{1}$ It is often called UV keratitis. ${ }^{2}$ Photokeratitis is a condition of the cornea's epithelial tissue injured by acute reversible radiation, including UV light radiation. ${ }^{1}$

The condition is marked by eye pain, a sensation of foreign objects in the eyes, discomfort when exposed to light (photophobia), watery eyes, and persistently twitching eyes. These symptoms can last for 6 to 12 hours and tend to disappear within 48 hours. Exposure to continuous light radiation can cause visual paralysis or vision loss, even blindness. ${ }^{1-3}$ Radiation derives from the sun as well as beam hazards and scattered radiation-producing machines and instruments. Non-sun sources such as welding, paint and ink curing techniques, tanning and LED lights, and the germicidal process of sterilization commonly found in hospitals and laboratories. ${ }^{1,3}$

Based on the U.S Bureau of Labor Statistics data, occupational eye injuries accounted for 27,450 (61.8\%) cases in 2008. Eye injuries caused by welding sparks con-

Correspondence $^{*}$ : Fajaria Nurcandra, Public Health Studies, Faculty of Health Science, Universitas Pembangunan Nasional Veteran Jakarta, RS Fatmawati Street, Pondok Labu, South Jakarta, DKI Jakarta, Indonesia, E-mail: fnurcandra@gmail.com, Phone: +62 89654211643 stituted $1,390(5.1 \%)$ cases, which later reported as photokeratitis. ${ }^{3}$ The annual incidence of occupational eye injury in Hong Kong was estimated at 8,000 or 125 cases per $100,000 .{ }^{4}$ Workplace injury rates comprised $9.1 \%$ of Indonesia's bodily injuries, based on that country's 2018 Basic Health Research, or Riset Kesehatan Dasar. ${ }^{5}$ The incidence of occupational accidents impacting the eye is not yet recorded in Indonesia. Riset Kesehatan Dasar in 2013 listed occupational eye injuries caused by sharp objects, blunt tools, and machines, falling objects, poisoning, radiation, burns, etc. In that year, eye injuries in Indonesia were reported to represent only $0.6 \%$ of total injuries among farmers, fishermen, and laborers. In West Java Province, the proportion of eye injuries is $0.7 \% .^{6}$

Photokeratitis is generally associated with UV radiation from manufacturing, construction, trade, production, installation, maintenance, and hospital and laboratory services. ${ }^{3}$ One of the jobs posing the highest risk of exposure to UV light is welding. Welding is a process for connecting metal pieces into the desired shape. The welding trade is needed for both small- and large-scale con-

Received : September 06, 2019

Accepted : September 11, 2020

Published: November 28, 2020 
struction. ${ }^{7}$ The welding process produces UV waves that can be absorbed by the eye's cornea, lens, and retina. ${ }^{8}$

Welding workers in the informal sector are vulnerable populations exposed to UV radiation. The lack of Occupational Health and Safety (OHS) oversight in the informal sector is due to the low level of guidance and programs for preventing occupational diseases and accidents. ${ }^{8,9}$ The current study focuses on the magnitude of radiation UV effects with photokeratitis complaints. The prevalence and risk of photokeratitis in Depok among informal welding workers have never been reported. This study aimed to determine UV radiation's effect on photokeratitis complaints in informal welding in Cimanggis Subdistrict, Depok, West Java, in 2019.

\section{Method}

A cross-sectional study was performed in 36 informal welding sector workshops in Cimanggis Subdistrict, Depok, West Java, Indonesia, in May-June 2019. A total of 100 informal welding workers were selected. Subjects were included if they were willing to work as welding workers for at least three months, were aged 17 years or more, and participated in the welding workshops. The main independent variable was UV radiation and photokeratitis.

This study carried out preliminary studies in the welding workshop in Cimanggis Subdistrict, Depok, West Java, in February 2019 in seven informal welding workshops with 20 welders. Through interviews with the welders, it was reported that 17 respondents were currently suffering eye complaints, and three others had had no eye complaints for the past three months. Symptoms were typically felt in red, sore, or "sandy" eyes and the feeling of a foreign object in the eye. They were felt after work and especially at night, so that participating workers had sleeping difficulty. These signs and symptoms are the characteristic of photokeratitis disease. ${ }^{1}$

Ultraviolet (UV) radiation was measured by UV meters of each subject. Ultraviolet radiation Threshold Limit Value (TLV) was based on the Regulation of Ministry of Labor Republic Indonesia No. 5 of 2019 concerning of Occupational Safety and Health in Occupational Environment. Ultraviolet exposure was divided using $\operatorname{TLV}\left(0.0001 \mathrm{~mW} / \mathrm{cm}^{2}\right)$. A semi-structured questionnaire was used to collect data about photokeratitis complaints, age, education level, eye protection, safety knowledge, and work period. Photokeratitis was determined based on an eight-point questionnaire on subject complaints about their eyes. Did they feel painful, red, blurry, gritty, sensitive to bright light, tearing, or twitching? Did their eyelids feel swollen? Welding distance was measured using a tube measure/meter. Eye protection was assessed through a questionnaire and confirmed through direct observation. Safety knowledge was identified through four questions: knowledge of occupational hazards, such as health and safety, protective equipment, and dangerous equipment; availability of PPE (Personal Protective Equipment); training; and the frequency of PPE use. Those questions were tested using statements such as, "There are always hazards with each occupation", "There is no hazardous exposure to eyes during the welding process", "UV radiation could impact the eyes' health condition", and "OHS should be involved in the prevention of disease and occupational injury". The age cut-off was 35 years because that is the age at which visual impairment often begins. High school and above were included as higher education. Cut-off points for working periods and welding distance were seven years and $45 \mathrm{~cm}$, respectively.

Statistical software was used to analyze each variable's distribution frequency and proportion, especially for photokeratitis and UV exposure. This study used $\alpha=$ 0.05 , power $80 \%$, odds ratio (OR), and $95 \%$ confidence intervals (CIs). A backward logistic regression was used to obtain a fit model of UV exposure effect on photokeratitis complaints. Confounders were identified by $10 \%$ differences between crude OR and adjusted OR. The study fulfilled the Health Research Ethics Commission's code of ethics, the Veteran National Development University of Jakarta with Number B/1899/5/2019/ KEPK, stipulated on May 10, 2019.

\section{Results}

The proportion of photokeratitis among informal welding workers was high (84\%). Most informal welders were exposed to UV light radiation higher than the TLV (76\%). The high proportion of UV light radiation exposure can lead to photokeratitis.

Table 1. Distribution of Photokeratitis Complaints and Ultraviolet Exposure among Welding Workers in Cimanggis Subdistrict, Depok, West Java, Indonesia

\begin{tabular}{|c|c|c|c|}
\hline \multirow{2}{*}{ Variable } & \multirow{2}{*}{ Category } & \multicolumn{2}{|c|}{ Total $(n=100)$} \\
\hline & & $\mathbf{n}$ & $\%$ \\
\hline \multirow[t]{2}{*}{ Photokeratitis } & Yes & 84 & 84 \\
\hline & No & 16 & 16.0 \\
\hline \multirow[t]{2}{*}{ Ultraviolet light radiation } & > Threshold limit value & 76 & 76.0 \\
\hline & $\leq$ Threshold limit value & 24 & 24.0 \\
\hline
\end{tabular}

Table 2. Distribution of Photokeratitis Complaints

\begin{tabular}{lcc}
\hline Photokeratitis Complaints & Frequency $(\mathbf{n}=\mathbf{1 0 0})$ & Percentage $(\%)$ \\
\hline Painful eyes & 84 & 18.1 \\
Red eyes & 74 & 15.9 \\
Blurred vision & 39 & 8.4 \\
Gritty feeling & 78 & 16.8 \\
Sensitivity to bright light & 57 & 12.3 \\
Swelling eyelids & 46 & 9.9 \\
Tearing eyes & 66 & 14.2 \\
Twitching eyes & 20 & 4.3 \\
\hline
\end{tabular}


Table 3. Crude Relationship between Variables and Photokeratitis Complaints among Welding Workers in Cimanggis Subdistrict, Depok, West Java, Indonesia

\begin{tabular}{|c|c|c|c|c|c|c|}
\hline \multirow{2}{*}{ Variable } & \multirow{2}{*}{ Category } & \multicolumn{2}{|c|}{ Photokeratitis Complaints } & \multirow{2}{*}{ Total } & \multirow{2}{*}{ p-value } & \multirow{2}{*}{ Crude OR $(95 \% \mathrm{CI})$} \\
\hline & & Yes & No & & & \\
\hline \multirow[t]{2}{*}{ Ultraviolet light radiation } & > Threshold limit value & $69(90.8 \%)$ & $7(9.2 \%)$ & $76(100 \%)$ & $0.003 *$ & $5.914(1.9-18.3)$ \\
\hline & $\leq$ Threshold limit value & $15(62.5 \%)$ & $9(37.5 \%)$ & $24(100 \%)$ & & \\
\hline Age & $>35$ years & $36(80.0 \%)$ & $9(20.0 \%)$ & $45(100 \%)$ & 0.476 & $0.583(0.1-1.7)$ \\
\hline Education level & High & $28(77.8 \%)$ & $8(22.2 \%)$ & $36(100 \%)$ & & \\
\hline \multirow[t]{2}{*}{ Eye protection } & No & $48(92.3 \%)$ & $4(7.7 \%)$ & $52(100 \%)$ & $0.037^{*}$ & $4.000(1.1-13.4)$ \\
\hline & Yes & $36(75.0 \%)$ & $12(25.0 \%)$ & $48(100 \%)$ & & \\
\hline \multirow[t]{2}{*}{ Safety knowledge } & Bad & $52(91.2 \%)$ & $5(8.8 \%)$ & $57(100 \%)$ & $0.046^{*}$ & $3.575(1.1-11.2)$ \\
\hline & Good & $32(74.4 \%)$ & $11(25.6 \%)$ & $43(100 \%)$ & & \\
\hline
\end{tabular}

Notes: *significant in $\alpha=0.05 ; \mathrm{OR}=$ Odd Ratio; $\mathrm{CI}=$ Confidence Interval

Table 4 Adjusted Effect of Ultraviolet Radiation Exposure and Photokeratitis Complaints

\begin{tabular}{lccccc}
\hline Variables & Coefficient $(\boldsymbol{\beta})$ & Z-Score $($ Wald) & SE & p-value & AdjOR (95\% CI)* \\
\hline Ultraviolet radiation > TLV & 1.979 & 7.415 & 0.727 & 0.006 & $7.236(1.74-30.07)$ \\
Low level of education & 1.134 & 2.466 & 0.722 & 0.116 & $3.108(0.75-12.79)$ \\
Poor eye protection & 1.100 & 2.678 & 0.672 & 0.102 & $3.004(0.80-11.21)$ \\
Limited OHS knowledge & 1.490 & 4.945 & 0.670 & 0.026 & $4.436(1.19-16.48)$ \\
Welding distance $\leq 45 \mathrm{~cm}$ & 0.481 & 0.473 & 0.700 & 0.492 & $1.618(0.41-6.37)$ \\
\hline
\end{tabular}

Notes: *Multivariate logistic regression analysis adjusted for education level, eye protection use, OHS knowledge, and welding distance; $\mathrm{SE}=$ Standard Error; AdjOR = Adjusted Odds Ratio; TLV = Threshold Limit Value; OHS = Occupational Health and Safety

Table 2 shows the proportion of each photokeratitis complaint. The majority of informal welding workers' complaints were variations of painful, gritty, red eyes, tearing, and sensitivity to bright light. The least complaint was twitching eyes.

Table 3 shows a little difference between the strata of workers' ages, education levels, eye protection, safety knowledge, working periods, and welding distances. Data on the age proportion of workers in this study were normal, and more than half of the subjects were aged $\leq 35$ years $(55.0 \%)$. Approximately 76 respondents who worked with UV radiation exceeded the TLV, while 69 subjects $(90.8 \%)$ experienced photokeratitis complaints. Working periods and welding distances had distributions so diffuse and broad that the distribution fell outside the Kolmogorov Smirnov test's normal range. Thus, the working period was classified through a normality test and took a median value of years, while the welding distance was given a median value of $45 \mathrm{~cm}$. The subjects majority had worked in the welding sector for $\leq 7$ years and welded at a distance of $\leq 45 \mathrm{~cm}$. More than half of the subjects had graduated from high school. The chisquare test obtained p-values of $0.003(\mathrm{OR}=5.914 ; 95 \%$ $\mathrm{CI}=1.9-18.3)$, which indicated a relationship between
UV radiation and photokeratitis complaints in welders. A chi-square test found a significant relationship between eye protection variables and safety knowledge to photokeratitis ( $p$-value $<0.05$ ), while other variables had $p$-values $>0.05$. That said, there was no relationship between the ages, levels of education, working periods, and welding distances with complaints of photokeratitis in Cimanggis Subdistrict welders.

After a logistic regression test, a significant effect of UV radiation during welding was the strong association with photokeratitis complaints, with adjustment by education level, eye protection, safety knowledge, and welding distance. This strong association was probably overestimated, and chance or systematic error was existed. Those could be seen through the wide confidence interval range. From the result, it was estimated that subjects who exceed TLV of UV radiation were 7.236 times likelier to suffer photokeratitis complaints than those exposed to $\mathrm{UV}$ radiation below the TLV.

\section{Discussion}

This study found that the number of welders in Cimanggis Subdistrict, Depok, West Java, who had experienced photokeratitis-type complaints, was relatively 
high. Many respondents had experienced eye complaints like pain, burning sensation, and the feeling that a foreign object or "sand" was within. This complaint was often felt at night after welding at work that day. Those high proportions were likely due to working welders' schedules in Cimanggis Subdistrict, which average 8-hour days and 7-day workweeks. The workers are often exposed to UV radiation every day.

The wavelength, high duration, and frequency are factors of UV radiation exposure that can impact the severity of corneal reactions and disorders. ${ }^{9}$ According to previous study, UV radiation exposure over 30 minutes puts the subject at risk of photokeratitis. ${ }^{10} \mathrm{UV}$ radiation exposure to the cornea will irritate the superficial corneal epithelium and inhibit the mitotic process. This irritation leads to an inflammatory response. The swelling will increase corneal thickness, resulting in changes to the corneal bias strength and visual obscurity. Recovery will occur approximately 72 hours after exposure. ${ }^{11}$ According to other research, symptoms can last for 6-12 hours and then disappear within 48 hours. However, high-intensity radiation exposure will cause visual paralysis or vision loss, even blindness. ${ }^{1}$ UV radiation cumulative exposure can lead to corneal epithelium damage. ${ }^{11}$

The percentage of subjects exposed to UV radiation exceeding the TLV was high. The majority of welding workers in Cimanggis Subdistrict used the electric arc welding method; $16.0 \%$ used argon (TIG). This type of electric welding carries considerable risk to respondents' health because it produces a fire containing UV and radiation in gas form. UV radiation measurement was usually done from 9:00 am-2:00 pm, at which time UV light can be especially intense. ${ }^{12}$ All welding activity was located outdoors, which also carries UV keratitis potential from increased sunlight exposure. ${ }^{2} \mathrm{~A}$ bright sky, when data is collected, can increase UV radiation intensity because the sun is a natural source of UV rays. ${ }^{1}$ Other influencing factors are seasons, the hemisphere, clouds, fog, and climate. 12

The percentage of welders in the Cimanggis Subdistrict who experienced photokeratitis complaints after exposure to UV radiation exceeding the TLV was high, and a relationship was found between UV radiation and photokeratitis complaints. This finding was supported by previousstudy conducted on PT PAL Indonesia Surabaya welding workers where the incidence of photokeratitis with UV radiation $>0.0001 \mathrm{~mW} / \mathrm{cm}^{2}$ was $43.48 \% .{ }^{13}$ Our proportional finding was higher, probably due to this study conducted within informal welding workers.

The logistic regression test obtained a significant relationship between UV radiation and photokeratitis complaints after controlling for confounding variables. Crude
OR was 5.914, whereas adjusted OR for UV radiation relationship with photokeratitis complaints after controlled confounding variables (level of education, eye protection, safety knowledge, and welding distance) was 7.236. There was a difference between POR before and after controlling confounding variables. Hence, this study found that UV radiation during welding was a primary risk factor of photokeratitis complaints. This finding coincides with a previous study, ${ }^{14}$ that found that photokeratitis risk factors include an intensity of exposure to high UV radiation carried a 5.55-fold magnitude risk. Age greater than 41 years carried 7.09 times the risk, workers who rarely consumed vitamin A bore 12.82 times the risk, those who did not use PPE had 29.41 times the risk, and an exposure of more than 8 hours carried 4.87 times the risk. ${ }^{14}$

The most dominant risk factor besides UV radiation was an improper use of PPE. ${ }^{14}$ More research in welders in North Samarinda reported that photo keratoconjunctivitis/PKC was strongly related to the duration of exposure to UV radiation. ${ }^{15} \mathrm{UV}$ radiation produced from welding arcs will create a high radiation spectrum that can have a significant impact on the worker's eyes. Furthermore, welding exposure can also impact those incidentally around the welding process. ${ }^{9}$

Eye disorders due to UV radiation exposure can be caused by a lack of prevention or eye protection. The emergence of eye disorders in these respondents is due to radiation intensity, distance from the welding arc, the angle at which radiation enters the eye, the type of eye protection used, or the failure to use eye protection at all. ${ }^{1}$ The subject's knowledge and education supported the use of eye protection in respondents. Workers with strong knowledge demonstrated increased awareness and safety practices at work. 16

Education strengthens a person's experience and skills to increase awareness of the importance of body health. ${ }^{17}$ Previous studies have found that workers with good academic and practical education tend to have no eye health problems. ${ }^{18}$ A high level of education can influence respondents to use eye PPE when welding. Educated welders also know the dangers of UV radiation in welding and how using protection can prevent eye disease, photokeratitis. The use of PPE is one of the proper steps for respondents in preventing and reducing health hazards. ${ }^{16}$ Education enhances safety knowledge, and that knowledge will influence the mindset and actions taken by workers in their work. ${ }^{16,19}$ So, to avoid photokeratitis, welders need safety training to improve their knowledge of occupational hazards and UV radiation prevention. ${ }^{16}$ Safety knowledge, attitudes, and practices can be related to the use of PPE. Training or intervention in safety knowledge can improve respondents/welder's safety status and use of PPE. ${ }^{19}$ Health promotion regard- 
ing the prevention of UV-related diseases should include information about the eyes, the dangers of UV rays, and the benefits of eye protection. This promotion can increase prevention, awareness, and selection behavior in optimal eye protection measures. ${ }^{12,20,21}$

Eye or face protectors can help respondents protect their eyes against UV radiation. Arc lightning or welding light can be avoided through eye protection, ${ }^{9}$ because UV radiation exposure without eye protection can cause eye complaints. The use of inadequate eye protection can cause the incidence of photokeratitis. ${ }^{2}$ Eye protection can effectively reduce the symptoms of UV keratitis. ${ }^{22}$ The use of eye protection or other types of spectacles can protect the eyes against UV radiation exposure. 1,23,24 Using spectacles can reduce UV radiation doses absorbed by the eye by $10 \%-25 \%$, compared to someone who does not use eye protection. ${ }^{1}$ Our subjects answered the questionnaire regarding the type of spectacles at $95.0 \%$ rate, but observations used eye protection only $48.0 \%$ of the time.

Welding is a considerable risk of exposure to UV radiation. The welding process produces a radiation spectrum of 200-1400 $\mathrm{nm}$. The radiation spectrum of UV light produced by welding has a wavelength of 200-400 nm. ${ }^{25}$ The cornea will absorb maximum UV radiation from approximately $310-280 \mathrm{~nm}, 22$ and a welding arc can produce a very high UV radiation spectrum within the working distance with a short welding arc. This radiation can potentially damage the eye organ or risk causing photokeratitis. ${ }^{26}$ Welding produces a broad spectrum of UV radiation within a short distance from the worker. ${ }^{1}$ Photokerato conjunctivitis is suffered by workers who weld at very close distances. Exposure to UV radiation in welding can affect subjects' eyes if the welding distance is close.

The bias which may appear in this study was non-differential misclassification since each respondent was interviewed and measured using the same instruments. Such bias may result in an underestimation of risk magnitude. This cross-sectional study is identical to temporal ambiguity about exposure and outcome. Despite that, the study can be generalized to the population at large and external populations with the same characteristics as this study population. This study probably overestimates results where the adjusted odds ratio appears higher than the actual value. That is caused by a cross-sectional study with a high proportion of outcomes analyzed using logistic regression. Furthermore, chance seems to exist, possibly due to unmeasured risk factors (extraneous variables).

\section{Conclusion}

This study showed that UV radiation, more than TLV, is the primary risk factor of photokeratitis. The risk to in- formal welding workers is higher than in formal or manufactured welding. The risk of photokeratitis complaints is influenced by education level variables, eye protection, safety knowledge, and welding distance.

\begin{abstract}
Abbreviations
UV: Ultraviolet; Riskesdas: Riset Kesehatan Dasar (Indonesias' Basic Health Research); OHS: Occupational Health and Safety; TLV: Threshold Limit Value; AdjOR: Adjusted Odds Ratio; PPE: Personal Protective Equipment; SE: Standard Error; CI: Confidence Interval.
\end{abstract}

Ethics Approval and Consent to Participate

Ethics approval was obtained from the Health Research Ethics Commission, Universitas Pembangunan Nasional Veteran Jakarta (B/1899/5/2019/KEPK), on 10 May 2019. Written informed consent was obtained from the subject of both groups for voluntary participation.

\section{Competing Interest}

Author declares that there are no significant competing financial, professional, or personal interests that might have affected the performance or presentation of the work described in this manuscript.

\section{Availability of Data and Materials}

Data are not available due to the ethical restrictions of the research. Participants of this study did not agree for their data to be shared publicly.

\section{Authors' Contribution}

Maria KIJ Yustheresani, Fajaria Nurcandra, Azizah Musliha Fitri, Dyah Utari were involved in conceptualizing and designing the study. Maria KIJ Yustheresani, Fajaria Nurcandra, Azizah Musliha Fitri, Annisa Ika Putri searched the literature. Maria KIJ Yustheresani, Fajaria Nurcandra, AMF prepared the questionnaire and collected the data. Maria KIJ Yustheresani, Fajaria Nurcandra, Dyah Utari analyzed the data and prepared the manuscript. Fajaria Nurcandra, Dyah Utari, Annisa Ika Putri reviewed the manuscript. All authors read and approved the final manuscript.

\section{Acknowledgment}

Thanks to Putri Permatasari, SKM, MKM (Head of Public Health Undergraduate Program, Faculty of Health Science, Universitas Pembangunan Nasional Veteran Jakarta), Government of Depok City for the permit and information of informal welding locations.

\section{References}

1. Moore LA, Hussey M, Ferreira JT, Wu B. Review of photokeratitis: corneal response to ultraviolet radiation (UVR) exposure. S Afr Optom. 2010; 69 (3): 123-31.

2. McIntosh SE, Guercio B, Tabin GC, Leemon D, Schimelpfenig T. Ultraviolet keratitis among mountaineers and outdoor recreationists. Wilderness Environ Med. 2011; 22 (2): 144-7.

3. Harris PM. Workplace injuries involving the eyes 2008. U.S. Bureu of Labor Statistics. 2011; 2 (1): 1-7. 
4. Cai M, Zhang J. Epidemiological Characteristics of work-related ocular trauma in Southwest region of China. Int J Environ Res Public Health. 2015; 12 (8): 9864-75.

5. Kementrian Kesehatan Republik Indonesia. Riset kesehatan dasar 2018. 2018; 61.

6. Kementrian Kesehatan Republik Indonesia. Pokok-pokok hasil riset kesehatan dasar Indonesia 2013; 2013.

7. Biji C, Jisha T, Lakshmy C, Praseetha PC, P RBB, Remya M, et al. Occupational health hazards in welders of Palakkad District: an appraisal. Indian Journal of Public Health Research and Development. 2013; 4 (2): 49-54.

8. Ramdan IM. Memperbaiki kondisi kesehatan dan keselamatan kerja sektor informal melalui program corporate social responsibility perusahaan. Jurnal Manajemen Pelayanan Kesehatan. 2012; 15 (01): 2 6.

9. Mgonja CT. The Effects of arc welding hazards to welders and people surrounding. Internationa Journal of Mechanical Engineering and Technology (IJMET). 2017; 8 (3): 433-41.

10. Finn LE, Gutowski J, Alles S, Mirowitz N, Johnson C, Osterhoudt KC, et al. photokeratitis linked to metal halide bulbs in two gymnasiums Philadelphia, Pennsylvania, 2011 and 2013. MMWR Morb Mortal Wkly Rep. 2016; 65 (11): 282-5.

11. Koyfman A, Long BJ. Ultraviolet keratitis clinical presentation: history, physical, causes; 2017 [cited 201912 January].

12. Izadi M, N JJ, Pourazizi M, Mh AA, Mj H. Photokeratitis induced by ultraviolet radiation in travelers: a major health problem. J Postgrad Med. 2018; 64: 40-7.

13. Kurniawan AF, Ma I, Sujoso ADP. Gejala fotokeratitis akut akibat radiasi sinar ultraviolet (UV) pada pekerja las di PT. PAL Indonesia Surabaya. IKESMA. 2017; 13 (1): 22-31.

14. Muskita M, Martiana T, Soedirham O. Analysis of photokeratitis-related risk factors in welders of PT. Pal Indonesia (Persero) Surabaya. Int J Res Eng Technol. 2015; 04 (04): 512-6. http://www.ijret.org

15. Ramdan IM, Mursydah SB, Jubaedah S. Photokeratoconjunctivitis symptoms among informal welding operators in North Samarinda, Indonesia. Global Medical \& Health Communication. 2017; 5 (2):
$144-51$.

16. Budhathoki SS, Singh SB, Sagtani RA, Niraula SR, Pokharel PK. Awareness of occupational hazards and use of safety measures among welders: a cross-sectional study from Eastern Nepal. BMJ Open. 2014; 4 (6): 1-7.

17. Kaplan RM, Spittel ML, David DH (eds). Population health: behavioral and social science insights/understanding of the relationship between education and health. AHRQ Publication. Rockville, MD: Agency for Healthcare Research and Quality and Office of Behavioral and Social Sciences Research, National Institutes of Health; 2015.

18. Biji C, Jisha T, Lakshmy C, Praseetha PC, P RBB, Remya M, et al. Occupational health hazards in welders of Palakkad district: an appraisal. Indian J Public Heal Res Dev. 2013; 4 (2): 49-54.

19. Esaiyas A, Sanbata H, Mekonnen Y. Occupational health and safetyrelated knowledge, attitude, and practice among wood and metal workers in Hawassa, Ethiopia. Annual Research \& Review in Biology. 2018; 22 (6): 1-9.

20. Graham AL, Lawrence WH, Sheehan M, Graham AL, Lawrence WH, Sheehan M, et al. Knowledge of sunlight effects on the eyes and protective behaviors in the general community. Ophthalmic Epidemiology. 2016; 6586.

21. Yam JCS, Kwok AKH. Ultraviolet light and ocular diseases. International Ophthalmology. 2014; 34 (2): 383-400.

22. Dehghani A, Ramsheh AR, Peyman A, Pourmohammadi R, Akhlaghi M, Rezaei L, et al. Bandage contact lens for ultraviolet light photokeratitis. International Journal of Medical Research \& Health Sciences. 2016; 5 (8): 285-7.

23. Sasaki H, Sakamoto Y, Schnider C, Fujita N, Hatsusaka N, Sliney DH, et al. UV-B exposure to the eye depending on solar altitude. Eye \& Contact Lens. 2011; 37 (4): 191-5.

24. Majdi M, Milani BY, Movahedan A, Wasielewski L, Djalilian AR. The role of ultraviolet radiation in the ocular system of mammals. Photonics. 2014; 347-68.

25. Canadian Centre for Occupational Health and Safety. Ultraviolet radiation; 2016.

26. Zoric L, Stojcic M. The influence of ultraviolet radiation on eye. 